\title{
Estudo das alterações morfológicas da glândula adrenal na caquexia neoplásica
}

\section{Study of morphological alterations of the adrenal glands in the neoplastic cachexia}

\author{
Eveline Aparecida Isquierdo Fonseca'; Marcelo Abbá Macioszek ${ }^{2}$; \\ Alexandre Yukio Saito ${ }^{3}$; Karina Garcia Cotrim"; Tânia Longo Mazzuco ${ }^{5 *}$
}

\begin{abstract}
Resumo
O câncer em estágio avançado cursa com alterações nutricionais e metabólicas que caracterizam o estado de caquexia neoplásica. Em situações de comprometimento da homeostasia, a glândula adrenal tem papel fundamental na resposta neuroendócrina. Para estudar as alterações morfológicas da adrenal no desenvolvimento do câncer associado à caquexia, utilizamos o modelo experimental de caquexia induzida pelo tumor de Walker-256 em ratos Wistar. Os animais foram sacrificados 12 dias após inoculação tumoral e as adrenais removidas para análise histopatológica por meio da coloração por hematoxilina-eosina. Foram avaliados os parâmetros nutricionais, índice de caquexia e peso das adrenais. Os animais com tumor apresentaram índice de caquexia de $16,6 \pm 4 \%$. A média do peso das adrenais foi significativamente maior no grupo tumor $(40 \mathrm{mg} \pm 10)$ do que no controle $(25 \mathrm{mg} \pm 3)$. O córtex adrenal dos animais com caquexia apresentou hipertrofia das camadas fasciculada e reticular, exibindo espongiócitos volumosos; a região medular apresentou congestão e estase vascular. Os resultados foram semelhantes nos animais do grupo pair fed e do grupo alimentado ad libitum. Animais com caquexia devido ao câncer apresentam comprometimento morfológico da glândula adrenal que exibe alterações relacionadas à resposta de estresse, compatíveis com maior secreção de catecolaminas e ativação do eixo hipotálamo-hipófise-adrenal.
\end{abstract}

Palavras-chave: Carcinoma 256 de Walker. Caquexia. Glândulas Supra-Renais. Eixo HPA.

\begin{abstract}
Advanced cancer occurs with nutritional and metabolic alterations that characterize neoplastic cachexia. When homeostasis is compromised, the adrenal glands have a fundamental role in the neuroendocrine response. Our purpose in this research was to study morphological alterations of the adrenal glands in the development of cancer associated to cachexia. Cachexia experimental model induced by Walker 256 tumor in Wistar rats, was used. Animals were sacrificed 12 days after tumor cells inoculation and adrenal glands removal for histopathologic analysis by means of hematoxylin and eosin stain. Nutritional parameters, cachexia index and adrenal glands weight, were evaluated. Animals with tumor presented cachexia index of $16,6 \pm 4 \%$. Adrenal glands average weight was significantly higher in the tumor group $(40 \mathrm{mg} \pm 10)$ than in the control group $(25 \mathrm{mg} \pm 3)$. Adrenal cortex of animals with cachexia showed hypertrophy of the zona fasciculata and reticular layer, with voluminous spongiocytes;
\end{abstract}

\footnotetext{
1 Bolsista de Iniciação Científica pela Universidade Estadual de Londrina (UEL); Londrina-PR.

2 Mestrando de Pós-graduação em Patologia Experimental pela Universidade Estadual de Londrina (CCB/UEL); Londrina-PR.

3 Professor (M.Sc.) Dpto. Ciências Patológicas (PAT) pela Universidade Estadual de Londrina (CCB/UEL); Londrina-PR.

4 Especialista em Farmacologia pela Universidade Norte do Paraná (UNOPAR); Londrina-PR.

5 Professora (Ph.D.) Pós-graduação em Patologia Experimental pela Universidade Estadual de Londrina (PAT/CCB/UEL). E-mail: tmazzuco@uel.brou tmazzuco@gmail.com

* Autor para correspondência
} 
vascular congestion and stasis were observed in the medullar region. Results were similar in the pair and ad libitum-fed groups. Animals with cancer cachexia showed compromised morphology of the adrenal glands which showed alterations related to stress response, suggesting increased cathecolamine secretion and activation of the hypothalamus-pituitary-adrenal axis.

Key words: Walker Carcinoma 256. Cachexia. Adrenal Glands. HPA axis.

\section{Introdução}

Câncer é o nome dado às neoplasias malignas, caracterizado por crescimento autônomo e desordenado de células que invadem os tecidos e órgãos, podendo espalhar-se para outras regiões do corpo (metástases) (BRASILEIRO FILHO, 2006). Atualmente, o câncer é uma das principais causas de morte em todo o mundo. De acordo com o Instituto Nacional do Câncer (2008), órgão do Ministério da Saúde, as neoplasias malignas atualmente são a $2^{\mathrm{a}}$ causa de morte por doença no Brasil, depois das doenças cardiovasculares. Estatísticas americanas estimam que 9 milhões de pacientes recebam o diagnóstico de câncer no mundo, a cada ano.

Além das alterações inflamatórias e imunitárias causadas pelo câncer, pode ocorrer uma situação de redução da ingestão alimentar e perda de massa muscular e adiposa caracterizando o estado de caquexia ( $k a k o s=$ mau, hexis=estado). Além disso, é comum a ocorrência de anorexia nesses pacientes, a qual consiste em perda de apetite, saciedade precoce, combinação de ambas ou alteração das preferências alimentares, levando à diminuição da ingesta (DAVIS, et al., 2004).

A síndrome da anorexia-caquexia é uma complicação freqüente no câncer em estágio avançado. Ela é caracterizada por um intenso consumo dos tecidos muscular e adiposo, com conseqüente perda involuntária de peso, além de anemia, astenia, balanço nitrogenado negativo, devido a alterações fisiológicas, metabólicas e imunológicas (TISDALE, 2000; TISDALE, 2001; FEARON; MOSES, 2002). Este quadro é intensificado pelas alterações no metabolismo dos nutrientes (carboidratos, proteínas e lipídios), alterações hormonais (leptina, NPY, MC, grelina), além do aumento das citocinas circulantes, como fator de necrose tumoral alfa (TNF- $\alpha$ ), interleucina-1 (IL-1), interleucina-6 (IL-6) e interferon gama (IFN- $\gamma$ ) (ARGILÉS et al., 2003; ARGILÉS et al., 2005; SILVA, 2006). A síndrome da anorexiacaquexia é uma condição clínica de difícil tratamento, e não é corrigível pela simples terapia nutricional. Observa-se um comprometimento da homeostasia que envolve uma série de respostas neuroendócrinas frente a esta síndrome, incluindo a ação hormonal da glândula adrenal. Tal resposta é controlada pelo sistema hipotálamo-hipófise-adrenal, conhecido como eixo HPA (hypothalamic-pituitary-adrenal) (REICHE; NUNES; MARIMOTO, 2004).

As glândulas adrenais são órgãos endócrinos pares, situados nos pólos superiores dos rins. Elas são formadas pelo parênquima glandular (córtex e medula) e por tecidos de sustentação, estruturas vasculares e nervos formando o estroma. $O$ córtex e a medula são duas regiões muito distintas na glândula adrenal. O córtex está subdividido em três partes (zona glomerular, fasciculada e reticular), sendo o sítio da síntese dos hormônios corticoesteróides. A medula adrenal, porção central da glândula, é composta por células cromafins, as quais sintetizam e secretam catecolaminas, especialmente adrenalina, além de outros neurormônios (IDELMAN; VERDETTI, 2000; STEWART, 2003).

O eixo HPA e o sistema simpático/adrenomedular são componentes fundamentais da reação de estresse (CHROUSOS, 1995). Em condições patológicas como o câncer, esta reação é mediada por citocinas inflamatórias que incluem o TNF- $\alpha$ e as IL-1 e IL-6. Essas são capazes de estimular a produção hipotalâmica do hormônio liberador de corticotrofina $(\mathrm{CRH})$ e então ativar o eixo HPA, aumentando a liberação do hormônio adrenocorticotrófico (ACTH) pela glândula hipófise. No córtex adrenal, 
o ACTH regula a secreção de glicocorticóides, que agem como hormônios anti-inflamatórios endógenos, além de influenciar o metabolismo glicídico, lipídico e protéico (ZALOGA, 2001; REICHE; NUNES; MARIMOTO, 2005). O principal hormônio glicocorticóide é o cortisol, na espécie humana, e a corticosterona, nos murinos (IDELMAN; VERDETTI, 2000).

De modo geral a glândula adrenal participa de duas maneiras na resposta de estresse: 1) resposta medular com secreção de adrenalina e noradrenalina sob influência do sistema nervoso autônomo; 2) resposta cortical com secreção de glicocorticóides sob influência do eixo HPA e da própria produção medular (parácrina) de catecolaminas (CHROUSOS, 1995; BORNSTEIN; CHROUSOS, 1999; CHIKANZA; GROSSMAN, 2000).

O modelo experimental de caquexia induzida pelo tumor sólido de Walker-256 vem sendo utilizado no estudo do comportamento morfo-funcional das glândulas adrenais em face do quadro de caquexia. Essas células tumorais inicialmente foram preparadas a partir de um carcinoma de surgimento espontâneo na glândula mamária de ratas albinas prenhas, desenvolvido pelo Prof. George Walker em 1928 (apud TALALAY; TAKANO; HUGGINS, 1952). Desde então, esta linhagem celular vem sendo mantida em larga escala na sua forma indiferenciada de carcinossarcoma altamente invasivo, e é um importante recurso na oncologia experimental, devido aos diversos aspectos referentes ao seu comportamento biológico, sua capacidade de induzir rapidamente um estado de caquexia neoplásica e suas alterações bioquímicas (TAYEK et al., 1986; FREITAS et al., 2001; PEREIRA et al., 2004).

Sendo assim, o objetivo desse trabalho foi estudar as alterações morfológicas da glândula adrenal, órgão alvo do eixo HPA, em animais com caquexia neoplásica, adotando o modelo experimental de caquexia induzida pelo tumor sólido de Walker256.

\section{Metodologia}

\section{Animais}

Foram utilizados ratos machos da linhagem Wistar, com peso corpóreo inicial entre 200 a 250g, fornecidos pelo Biotério Central do Centro de Ciências Biológicas. Os ratos foram aclimatizados por 1 semana e mantidos no biotério setorial do Departamento de Ciências Patológicas da Universidade Estadual de Londrina, abrigados a $24^{\circ}$ C, com ciclo claro-escuro de 12 horas e com acesso a água e alimento ad libitum.

Posteriormente, os animais foram divididos em três grupos - um grupo com tumor de Walker-256 e dois grupos controle negativo (sem tumor): $a d$ libitum e pair fed. Os animais do grupo "tumor", assim como o grupo ad libitum, receberam ração à vontade $(52 \%$ de carboidratos, $21 \%$ de proteínas e $4 \%$ de gorduras) e animais do grupo pair fed receberam quantidade de ração equivalente àquela ingerida pelos animais com tumor.

O presente trabalho foi aprovado pelo comitê de ética e está cadastrado sob o $n^{\circ}$ 43/07 (CEEA/ UEL).

\section{Células neoplásicas}

Foi utilizada a linhagem de células tumorais do carcinossarcoma de Walker-256 (LLC-WRC 256), mantido no laboratório de Fisiopatologia dos Radicais Livres deste Departamento. O estoque de células foi mantido por meio de passagens semanais por inoculação asséptica intraperitoneal de $2 \times 10^{6}$ células/rato. A cada 7 dias, o exsudato peritoneal foi retirado e submetido à centrifugação diferencial a $4^{\circ} \mathrm{C}$ para separação das células tumorais, as quais foram suspensas em tampão fosfato-salina (PBS) $\mathrm{pH} 7,4 \mathrm{a} 4^{\circ} \mathrm{C}$. A viabilidade celular foi avaliada pelo método de exclusão do corante vital azul de tripan seguida de contagem em câmara de Neubauer. 


\section{Inoculação e crescimento tumoral}

Os animais foram previamente anestesiados por inalação com éter etílico e uma suspensão de 8,0 x $10^{7}$ células de Walker-256 em $500 \mu \mathrm{L}$ foi injetada no espaço subcutâneo utilizando-se seringa com agulha $30 \mathrm{G}$, na região posterior do flanco direito. Os animais dos grupos controle negativo receberam uma injeção do mesmo volume contendo apenas PBS.

Esses animais foram mantidos em gaiolas individuais para controle do consumo de ração. Além disso, o seguimento diário dos animais incluiu aferição diária do peso ponderal, avaliação do estado geral dos animais e acompanhamento do crescimento da massa tumoral por palpação e aspecto macroscópico.

Por fim, os animais foram avaliados durante 12 dias e após o sacrifício, foi analisada a morfologia da glândula adrenal, através de cortes histológicos, bem como os valores ponderais dos animais, dos tumores e das adrenais.

\section{Sacrificio dos animais e coleta de amostras}

Os animais foram sacrificados 12 dias após a inoculação tumoral. Após a anestesia com éter etílico, os animais receberam injeção intra-cardíaca de solução de $\mathrm{KCl}$ 10\%. Em seguida, foi realizada necropsia minuciosa, incluindo dissecação e avaliação macroscópica da massa tumoral e aferição do seu peso. As glândulas adrenais foram localizadas e cuidadosamente dissecadas para remoção da gordura adjacente e posterior aferição do peso. Em seguida, as mesmas foram seccionadas longitudinalmente no seu maior diâmetro e fixadas em paraformaldeído $4 \%$.

\section{Índice de caquexia}

Para o cálculo da alteração ponderal da massa corpórea dos animais (índice de caquexia), foi utilizada a seguinte fórmula: \% perda de massa corpórea $=($ mie $-\mathrm{mfe}+\mathrm{mt}+\mathrm{gmc}) \times 100 /(\mathrm{mie}+$ gmc), sendo: mie $=$ massa corpórea inicial do rato, $\mathrm{mfe}=$ massa corpórea final do rato inoculado com o tumor, $\mathrm{mt}=$ massa do tumor, $\mathrm{gmc}=$ ganho de massa do rato controle.

Os animais foram considerados caquéticos quando apresentaram uma perda de massa corpórea maior que $10 \%$.

\section{Processamento e análise histopatológica}

Após fixação por 12-24 horas com Bouin, as adrenais foram processadas pelas técnicas tradicionais de inclusão em parafina, realizado cortes histopatológicos de $5 \mu \mathrm{m}$ e corados pelo método hematoxilina-eosina (H\&E).

As lâminas foram analisadas em microscópio óptico Olympus $\mathrm{CH} 30$, utilizando-se objetivas de 5, 10 e 40 vezes, por meio de avaliação global da glândula e de análise comparativa do córtex e da medula, separadamente. Em seguida, foram fotografados utilizando câmera fotográfica digital (Cannon, PowerShot A70) adaptada ao microscópio, utilizando zoom óptico de 4X com qualidade de 1,3 megaPixel. Foi adicionada escala micrometrada às imagens fotografadas, e a área $\left(\mathrm{mm}^{2}\right)$ das regiões da glândula adrenal foi calculada utilizando o programa Image-Pro Plus v.5.0.2.9, MediaCybernetics.

\section{Análises estatísticas}

As variáveis qualitativas foram inicialmente analisadas de modo descritivo. Para as variáveis quantitativas, em planilhas do programa Excel 2003, foi observado o valor máximo e mínimo, o cálculo das médias e o erro-padrão da média. A hipótese de igualdade de médias entre dois grupos foi verificada por meio do teste " $t$ " de Student e entre três ou mais grupos por meio de análise de variância (ANOVA), utilizando o programa GraphPad Prism 4. O nível de significância foi considerado como $p<0,05$. Foi utilizado um espaço amostral de cinco animais em cada grupo. 


\section{Resultados e discussão}

Após a inoculação de células do tumor de Walker-256, ou de veículo nos grupos "controle", os animais foram acompanhados e pesados diariamente (Figura 1). A partir do quinto dia, os animais do grupo tumor começaram a apresentar aumento de volume da massa tumoral, identificado macroscopicamente, na região do inóculo (dados não apresentados). O ganho de peso corporal, de forma progressiva, foi observado apenas nos animais do grupo controle ad libitum (Figura 1). Pelo fato de ocorrer anorexia nos animais portadores de tumor, diminuindo sua ingestão alimentar, foi realizado um controle adicional denominado pair fed, necessário para avaliar a contribuição da anorexia para a perda de massa corpórea dos animais com caquexia neoplásica. Os animais portadores de tumor apresentaram índice de caquexia média de $16,6( \pm 4,65) \%$, associado à redução significativa da ingestão alimentar (Tabela 1), confirmando a presença da síndrome da anorexia-caquexia. A média de peso diário do grupo controle pair fed foi ainda inferior à do grupo tumor (Figura 1), apesar de não haver diferença estatisticamente significativa. Isso se justifica pelo fato de que o peso corporal diário dos animais com tumor não se refere apenas ao peso da carcaça, mas inclui o peso da massa tumoral, de crescimento progressivo. O peso médio do tumor no dia do sacrifício $\left(12^{\circ}\right.$ dia) foi de $12,73( \pm 4,59) \mathrm{g}$.

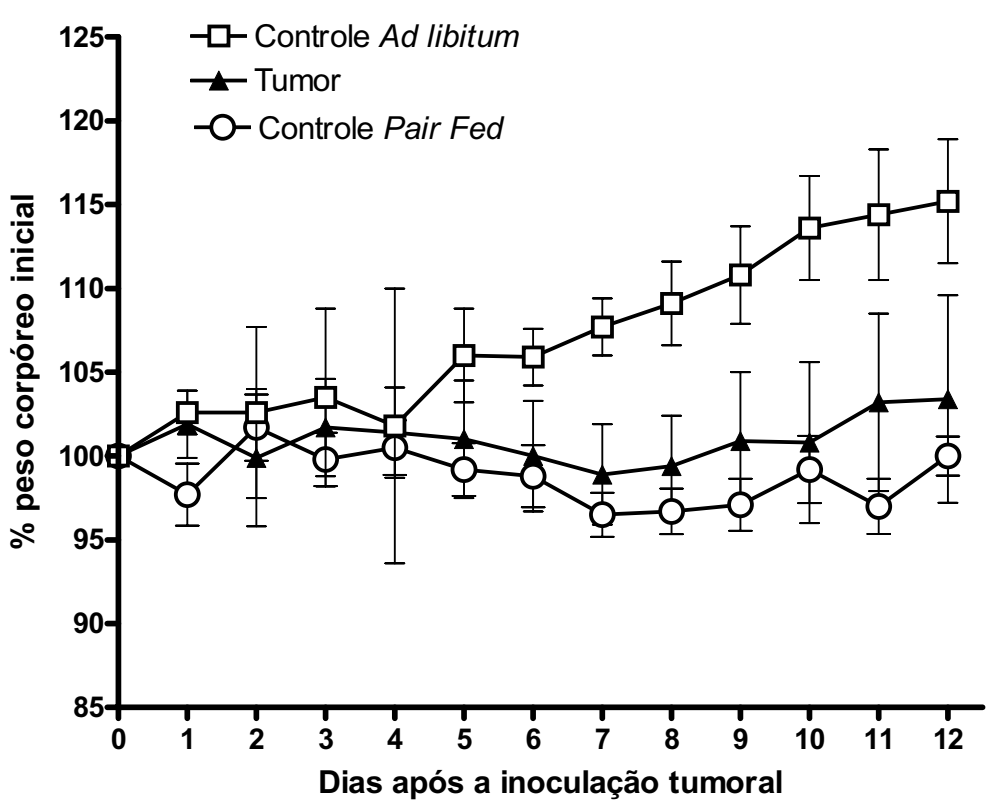

Figura 1. Média da porcentagem de peso corporal diário em relação ao peso inicial dos animais de cada grupo. $\mathrm{P}>0,05$ para Tumor $v s$. Controle Pair fed; $\mathrm{p}<0,001$ para controle Ad libitum em relação aos demais grupos (ANOVA).

Segundo os dados da tabela 1, pode-se observar que somente houve ganho de peso da carcaça no grupo de animais sem tumor Ad libitum (controle), correspondendo ao maior consumo de ração durante os 12 dias. Por outro lado, apesar do aumento de peso corporal final nos animais com tumor (Tabela 1), não houve ganho de peso da carcaça. Nossos dados demonstram uma diminuição gradativa do consumo diário de ração nesse grupo (resultados não apresentados), o que, associado ao índice de caquexia superior a $10 \%$, confirma a presença da síndrome anorexia-caquexia nos animais estudados. Diversos fatores levam à essa síndrome, como perda do apetite, alterações do paladar e olfato, saciedade precoce, bem como substâncias liberadas pelo tumor, pelo hospedeiro, e elevação das taxas de mobilização de gordura, além de perda de tecido muscular (SILVA, 2006). 
Tabela 1. Análise dos parâmetros corporais, ingestão alimentar e eficiência alimentar de ratos portadores de tumor de Walker-256 (Tumor) e ratos sem tumor (Pair fed e Ad libitum).

\begin{tabular}{|c|c|c|c|c|c|}
\hline \multirow{2}{*}{ Grupos } & \multicolumn{2}{|c|}{ Peso corporal (g) } & \multirow{2}{*}{$\begin{array}{l}\text { Ganho de peso da } \\
\text { carcaça }(g)^{\mathrm{a}}\end{array}$} & \multirow{2}{*}{$\begin{array}{l}\text { Consumo } \\
\text { total de ração }\end{array}$} & \multirow{2}{*}{$\begin{array}{c}\text { Eficiência } \\
\text { Alimentar }^{b}\end{array}$} \\
\hline & Inicial & final & & & \\
\hline $\begin{array}{l}\text { Controle } \\
\text { Ad libitum }\end{array}$ & $\begin{array}{c}235,86 \\
( \pm 12,45)\end{array}$ & $\begin{array}{c}271,24 \\
( \pm 6,18)\end{array}$ & $\begin{array}{c}35,38 \\
( \pm 7,27)\end{array}$ & $\begin{array}{c}235,76 \\
( \pm 69,20)\end{array}$ & $\begin{array}{c}1,88 \\
( \pm 0,54)\end{array}$ \\
\hline Tumor & $\begin{array}{c}214,61 \\
( \pm 20,56)\end{array}$ & $\begin{array}{c}220,99 \\
( \pm 17,44)\end{array}$ & $\begin{array}{c}-6,35 \\
( \pm 13,37)\end{array}$ & $\begin{array}{c}172,40 \\
( \pm 36,80)\end{array}$ & $\begin{array}{c}-0,85 \\
( \pm 1,37)\end{array}$ \\
\hline $\begin{array}{l}\text { Controle Pair } \\
\text { fed }\end{array}$ & $\begin{array}{c}248,90 \\
( \pm 22,31) \\
\end{array}$ & $\begin{array}{c}248,54 \\
( \pm 21,12) \\
\end{array}$ & $\begin{array}{c}-0,36 \\
( \pm 2,66)\end{array}$ & $\begin{array}{c}164,94 \\
( \pm 2,50)\end{array}$ & $\begin{array}{c}-0,03 \\
( \pm 0,20)\end{array}$ \\
\hline ANOVA & $\mathrm{p}<0,05$ & $\mathrm{p}<0,05$ & $\mathrm{p}<0,05$ & $\mathrm{~ns}^{\mathrm{c}}$ & $\mathrm{p}<0,01$ \\
\hline
\end{tabular}

Os resultados estão expressos pela média \pm erro padrão. ${ }^{a}$ Ganho de peso da carcaça $=$ Peso corporal final - peso corporal inicial peso do tumor da carcaça. ${ }^{b}$ Eficiência alimentar é a razão entre o ganho de peso corporal $(\mathrm{g})$ e a quantidade de alimento ingerido (g). ${ }^{\mathrm{c} n s}=$ diferença estatística não significativa.

Os animais sem tumor do grupo controle pair fed mantiveram o peso corporal estável durante todo o período, mesmo tendo recebido quantidade de ração limitada, semelhante à quantidade de ração consumida pelo grupo de animais com tumor. Isso mostra a adaptação metabólica à restrição alimentar pelos animais sem tumor, os quais conseguiram equilibrar o peso corpóreo com a quantidade de nutrientes disponíveis para suas necessidades diárias. A eficiência alimentar próxima de zero (Tabela 1) demonstra que todo alimento ingerido foi utilizado para as funções básicas e de sobrevida do animal.

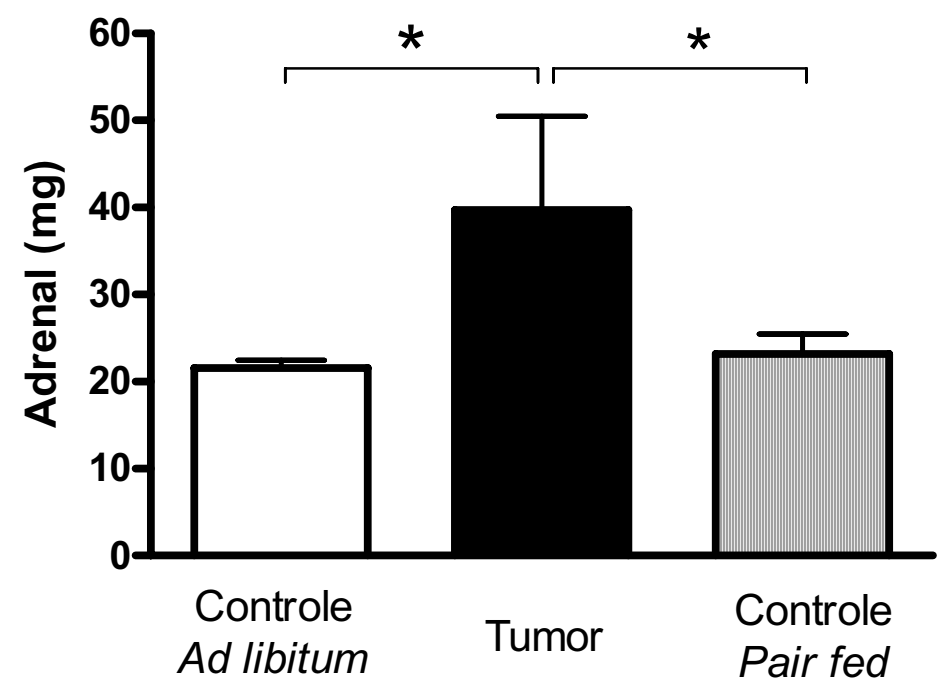

Figura 2. Média do peso das glândulas adrenais dos ratos dos três grupos analisados. $* \mathrm{p}<0,01$ (ANOVA). 
No estudo morfológico das glândulas adrenais, nossos resultados demonstram que o seu peso médio foi significativamente maior no grupo tumor em relação aos controles (Figura 2). A relação média entre o peso da adrenal e o peso final dos animais, também foi maior nos animais com tumor $(18,15 \pm 5,58 \%)$ comparado aos animais controle ad libitum e pair fed $(8,05 \pm 0,84 \%$ e $9,02 \pm 1,99 \%$, respectivamente). A glândula adrenal é de fundamental importância na manutenção da homeostasia; assim, na presença de uma doença neoplásica, podem ocorrer alterações na sua morfologia como uma resposta ao estresse gerado pelo tumor. Essa glândula é dividida em duas regiões córtex e medula, nas quais há a produção de diversos hormônios que contribuem para a homeostasia: os corticoesteróides e as catecolaminas, respectivamente. A relação entre as dimensões do córtex e da medula nos fornece uma estimativa do estado funcional dessas regiões. A semelhança do tamanho da região medular associada ao aumento do córtex no grupo tumor (Figura 3) é compatível com o efeito do estresse crônico (ULRICH-LAI et al., 2006). O maior peso das adrenais nos animais com tumor (Figura 2) sugere hipertrofia adrenal como conseqüência da resposta da glândula à presença do tumor. Essa hipertrofia ocorreu às custas de um aumento da área do córtex adrenal (Figura 3) comparado aos grupos controle (ad libitum e pair fed).

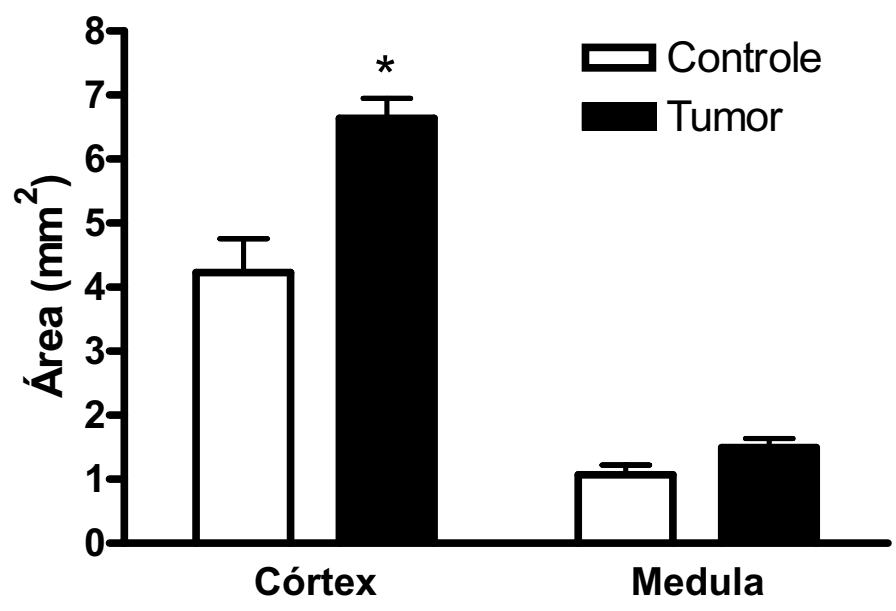

Figura 3. Relação entre a área do córtex e da medula adrenal em cortes histológicos das glândulas dos grupos Controle (Ad libitum e Pair fed) e Tumor. * $\mathrm{p}<0,05$ em relação ao controle (teste " $\mathrm{t}$ " de Student).

O córtex adrenal possui três zonas bem distintas. A zona glomerular ou glomerulosa é a camada mais externa, que corresponde a $5-10 \%$ do córtex, formada por células pequenas e arredondadas com núcleo denso. É o local de síntese dos hormônios mineralocorticóides, cujo principal representante é a aldosterona (IDELMAN; VERDETTI, 2000). A zona fasciculada é a camada intermediária, e ocupa dois terços da espessura do córtex, composta de cordões de células ricas em lipídios. Durante o processamento histológico para inclusão em parafina, as gotículas lipídicas são dissolvidas, dando às células um aspecto esponjoso, e por isso são também chamadas de "espongiócitos". Essas células apresentam núcleos densos e a razão núcleo/ citoplasmaé pequena, devido à presença das gotículas lipídicas citoplasmáticas. A camada fasciculada é o principal local de síntese dos hormônios glicocorticóides, cujos representantes principais são o cortisol (nos humanos) e a corticosterona (nos murinos) (NUSSDORFER, 1986). Por fim, a zona reticular ou reticulada, camada mais interna do córtex, está organizada na forma de uma rede anastomosada de traves celulares curtas, circundadas 
de capilares entremeados. As células apresentam um tamanho intermediário se comparado às células das zonas glomerular e fasciculada e possuem uma carga lipídica relativamente baixa, por isso recebem a denominação de "células compactas" (NEVILLE; O'HARE, 1985). Nessa região ocorre produção de esteróides sexuais (estrogênios e androgênios) e de umapequenaparceladeglicocorticóides(IDELMAN; VERDETTI, 2000; STEWART, 2003).
À microscopia, o córtex adrenal dos animais com caquexia apresentou as três zonas identificáveis, porém com hipertrofia das camadas fasciculada e reticular (Figura 4). Na zona fasciculada salientavam-se espongiócitos volumosos e algumas pequenas áreas sugestivas de necrose. Em nenhum dos casos foi observada metástase para a adrenal.

\section{Controle}

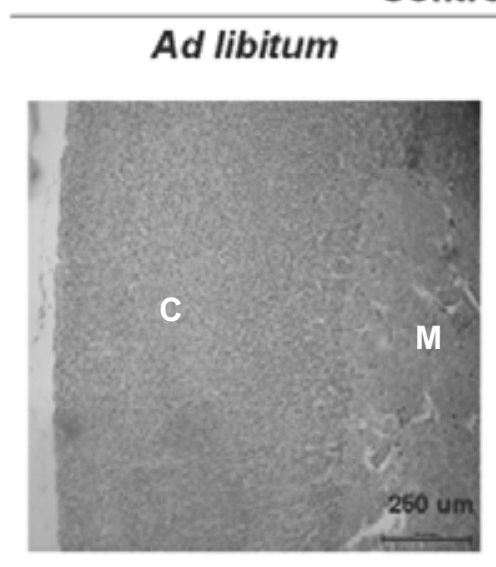

\section{Pair Fed}

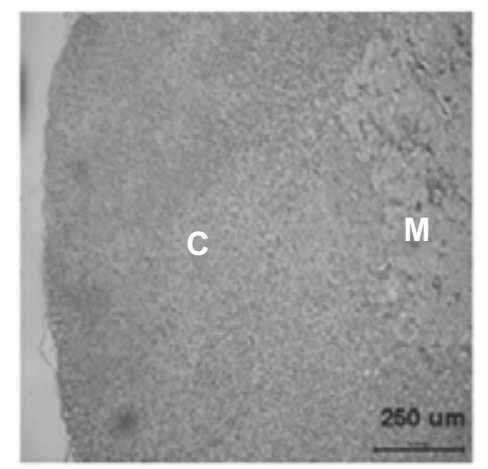

Tumor

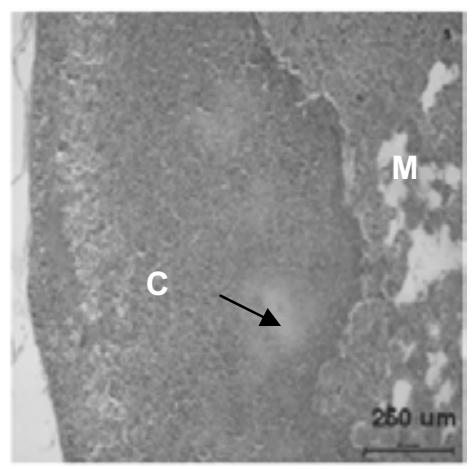

Figura 4. Fotomicrografias panorâmicas representativas das glândulas adrenais dos três grupos de animais. As imagens exibem a região cortical (C) e parte da região medular (M) da glândula de animais controle Ad libitum, controle Pair fed e grupo tumor. Pode-se observar na adrenal do grupo tumor uma distribuição desigual das três zonas da região cortical: predominância da região reticulada, diminuição da zona glomerular e hiperplasia da zona fasciculada com presença de espongiócitos. Região de necrose indicada na seta.

Não houve diferença significativa na morfologia da área medular das glândulas adrenais entre os grupos analisados. Porém, algumas alterações microscópicas foram observadas, como congestão vascular e deposição de hemossiderina (Figura 5). A congestão ou estase vascular pode ser a conseqüência da ação do CRH uma vez que esse hormônio atua como um potente agente vasodilatador na glândula adrenal (JONES, 1990). A deposição de hemossiderina pode ser explicada pela degradação da hemoglobina nos locais de congestão vascular observados na medula adrenal, uma região altamente vascularizada na glândula normal. 

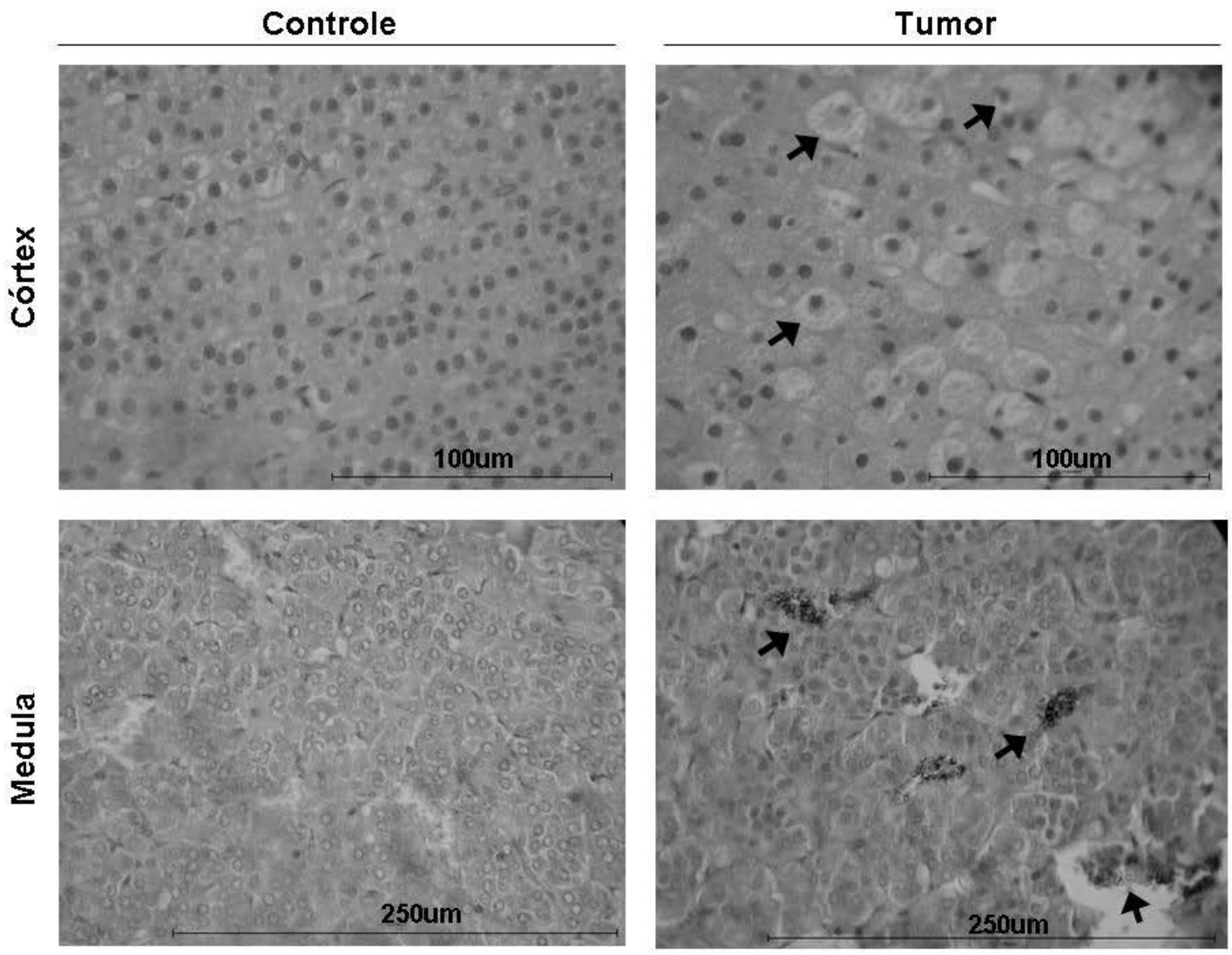

Figura 5. Fotomicrografias representativas das regiões da glândula adrenal de animal controle e portador de tumor. Região do córtex adrenal de animal sem tumor, mostrando a presença de espongiócitos normais. Na imagem superior direita, observa-se grande quantidade de espongiócitos presentes (setas) no córtex adrenal de animal com tumor. Região medular da adrenal de animal sem tumor (controle) à esquerda ou com tumor, à direita, mostrando depósito de hemossiderina (setas) e congestão vascular.

Em processos patológicos como o câncer, há o estímulo contínuo do eixo HPA, devido ao estresse e ao estado inflamatório, o que leva à produção prolongada de ACTH (CHROUSOS, 1995). Essa exposição ao ACTH pode causar hipertrofia da camada cortical adrenal, o que explicaria os resultados encontrados neste trabalho. A ação do ACTH possui dois mecanismos que contribuem para hipertrofia: efeito antiapoptótico e aumento da expressão e secreção do fator de crescimento endotelial vascular (VEGF) que tem ação sobre as células endoteliais (THOMAS, 2004). Além disso, níveis elevados de IGF-I (fator de crecimento semelhante à insulina - Insulin-like growth factor) plasmático podem ser produzidos por células tumorais, o que também levaria a uma hipertrofia adrenocortical (MESIANO, 1997; OTSUKA, 1999).

Esses dados mostram que a responsividade do eixo HPA pode trazer repercussões sobre o estado geral e neurovegetativo; a regulação entre o consumo de alimento, o apetite e o gasto energético; a resposta antitumoral do hospedeiro e a resposta antiinflamatória do organismo. Dessa forma, a hipertrofia cortical da glândula adrenal, especialmente nas zonas mais sensíveis ao ACTH, traduz a hiperresponsividade do eixo HPA no estado de caquexia neoplásica no modelo estudado. 


\section{Agradecimentos}

Eveline Aparecida Isquierdo Fonseca foi bolsista do Programa de Iniciação Científica - PIBIC/ CNPq-UEL. Este projeto recebeu apoio financeiro da fundação FAEPE/UEL 02/2007 - programa Grupos de Pesquisa. Agradecemos ao Prof. Rubens Cecchini (PAT/CCB/UEL) pelas células tumorais de Walker 256, bem como a Pedro Dionizio Filho e Jesus Vargas pelo excelente apoio técnico ao longo deste trabalho.

\section{Referências}

ARGILÉS, J. M.; BUSQUETS, S.; GARCÍAMARTÍNEZ, C.; LÓPEZ-SORIANO, F. J. Mediators involved in the cancer anorexia-cachexia syndrome: past, present, and future. Nutrition, Tarrytown, v. 21, n. 9, p. 977-985, 2005. -ARGILÉS, J. M.; MOORECARRASCO, R.; BUSQUETS, S.; LÓPEZ-SORIANO, F. J. Catabolic mediators as targets for cancer cachexia. Drug Discovery Today, Oxford, v. 8, n. 18, p. 838-844, 2003.

BORNSTEIN, S. R.; CHROUSOS, G. P. Clinical review 104: Adrenocorticotropin (ACTH)- and non-ACTHmediated regulation of the adrenal cortex: neural and immune imputs. Journal of Clinical Endocrinology \& Metabolism, Baltimore, v. 84, n. 5, p. 1729-1736, May. 1999.

BRASILEIRO FILHO, G. Bogliolo: Patologia. 7. ed. Rio de Janeiro: Guanabara Koogan, p. 188-236, 2006.

CHIKANZA, I. C.; GROSSMAN, A. B. Reciprocal interactions between the neuroendrocrine and immune systems during inflammation. Rheumatic Disease Clinics of North America, Philadelphia, v. 26, n. 4, p. 693-711, Nov. 2000.

CHROUSOS, G. P. The hypothalamic-pituitary-adrenal axis and immune-mediated inflammation. New England Journal of Medicine, Melbourn, v. 332, n. 20, p. 13511362, May. 1995.

DAVIS, M. P.; DREICER, R.; WALSH, D.; LAGMAN, R.; LEGRAND, S. B. Appetite and cancer-associated anorexia: a review. Journal of Clinical Oncology, New York, v. 22, n. 8, p. 1510-1517, Apr. 2004.

FEARON, K. C.; MOSES, A. G. Cancer cachexia. International Journal of Cardiology, Amsterdam, v. 85, n. 1, p. 73-81, Sep. 2002.
FREITAS, J. J. S.; POMPÉIA, C.; MIYASAKA, C. K.; CURI, R. Walker-256 tumor growth causes oxidative stress in rat brain. Journal of Neurochemistry, Oxford, v. 77, n. 2, p. 655-663, 2001.

IDELMAN, S.; VERDETTI, J. Chapitre 6: Les glandes surrénales. In: Endocrinologie et communications cellulaires. Grenoble: EDP Sciences, 2000. 584 p.

INSTITUTO NACIONAL DO CÂNCER - INCA. Estimativa 2008 - Incidência de Câncer no Brasil - INCA. Disponível em:< http://www.inca.gov.br/estimativa/ 2008>. Acesso em: 23 abr. 2008.

JONES, S.A.; CHALLIS, J.R. Steroid, corticotrophinreleasing hormone, ACTH and prostaglandin interations in the amnion and placenta of early pregnancy in man. $J$ Endocrinol, v. 125(1), p. 153-159, 1990.

MESIANO, S.; KATZ, S.L.; LEE, J.Y.; JAFFE, R.B. Insulin-like growth factors augment steroid production and expression of steroidogenic enzymes in human fetal adreno cortical cell: implications for adrenal androgen regulation. Journal of Clinical Endocrinology \& Metabolism, San Francisco, v. 82(5), p. 1390-1396, 1997.

NEVILLE, A. M.; O'HARE, M. J. Histopathology of the human adrenal cortex. Journal of Clinical Endocrinology \& Metabolism, Baltimore, v. 14, n. 4, p. 791-820, Nov. 1985.

NUSSDORFER, G. G. Cytophysiology of the adrenal cortex. International Review of Cytology, New York, v. 98, n. 1, p. 1-405, 1986.

OTSUKA, F.; TAMIYA, T.; YAMAUCHI, T.; OGURA, T.; OHMOTO, T.; MAKINO, H. Quantitative analysis of growth-related factors in human pituitary adenomas. Lowered insulin-like growth factor-I and its receptor mRNA in growth hormone-producing adenomas. Regulatory Peptides, Japan v. 83(1), v. 31-38, 1999.

PEREIRA, S. R. C.; DARRONQUI, E.; CONSTANTIN, J.; SILVA, M. H. R. A.; YAMAMOTO, N. S.; BRACHT, A. The urea cycle and related pathways in the liver of Walker-256 tumor-bearing rats. Biochimica et Biophysica Acta, Amsterdam, v. 1688, n. 3, p. 187-196, 2004.

REICHE, E. M. V.; NUNES, S. O. V.; MORIMOTO, H. $\mathrm{K}$. Stress, depression, the immne system, and cancer. The Lancet Oncology, London, v. 5, n. 10, p. 617-625, 2004.

REICHE, E. M. V.; NUNES, S. O. V.; MORIMOTO, H. K. Disfunções no Sistema Imune Induzidas pelo Estresse e Depressão: Inplicações no Desenvolvimento e Progressão do Câncer. Revista Brasileira de Oncologia Clínica, Belo Horizonte, v. 1, n. 1, p. 19-28, 2005. 
SILVA, M. P. N. Síndrome da anorexia-caquexia em portadores de câncer. Revista Brasileira de Cancerologia, Rio de Janeiro, v. 52, n. 1, p. 59-77, 2006.

STEWART, P. M. Chapter 14: The Adrenal Cortex. In: LARSEN, P. R.; KRONENBERG, H. M.; MELMED, S.; POLONSKY, K. S. Williams Textbook of Endocrinology. 10 th ed. Philadelphia: Saunders Elsevier, 2003. p. 491551.

TALALAY, P.; TAKANO, G. M. V.; HUGGINS, C. Studies on the Walker Tumor. I. Standardization on the Growth of a Transplantable Tumor. Cancer Research, Baltimore, v. 12, n. 11, p. 834-837, 1952

TAYEK, J. A.; ISTFAN, N. W.; JONES, C. T.; HAMAWY, K. J.; BISTRIAN, B. R.; BLACKBURN, G. L. Influence of Walker-256 carcinosarcoma on muscle, tumor, and whole-body protein synthesis and growth rate in the cancer-bearing rat. Cancer Research, Baltimore, v. 46, n. 11, p. 5649-5654, 1986.
THOMAS, M.; KERAMIDAS, M.; MONCHAUX, E.; FEIGE, J.J. Dual hormonal regulation of endocrine tissue mass and vasculature by adrenocorticotropin in the adrenal cortex. Endocrinology, France, v. 145(9), p. 4320-4329, 2004.

TISDALE, M. J. Metabolic abnormalities in cachexia and anorexia. Nutrition, Tarrytown, v. 16, n. 10, p. 10131014, 2000.

TISDALE, M. J. DSc, Câncer Anorexia and Caquexia. Nutrition, Tarrytown, v. 17, n. 5, p. 430-442, 2001.

ULRICH-LAI, Y.M.; FIGUEIREDO, H.F.; OSTRANDER, M.M.; CHOI, D.C.; ENGELAND, W.C.; HERMAN, J.P. Chronic stress induces adrenal hyperplasia and hypertrophy in a subregion-specific manner. American Journal of Physiology - Endocrinology And Metabolism, Cincinnati, v. 291(5), p. E965-E973, 2006.

ZALOGA, G. P. Sepsis-induced adrenal deficiency syndrome. Critical Care Medicine, Philadelphia, v. 29, n. 3, p. 688-690, 2001. 
